\title{
CIENCIA EXPERIMENTAL Y LEYENDA EN LOS LIBROS DE ZOOLOGIA DEL FONDO DE FELIPE II EN LA BIBLIOTECA DE EL ESCORIAL: HACIA UNA NUEVA SINTESIS*
}

\author{
José Luis Checa Cremades
}

\section{El libro naturalista del Renacimiento: Tradición y modernidad}

La masiva organización de nociones ya adquiridas desde la antigüedad clásica sobre los animales y vegetales y su incremento, determinado por la incesante multiplicación de nuevas especies que llegan a Europa gracias a los viajes (1) y a los descubrimientos en el Nuevo Mundo (2), mueve a los naturalistas del siglo XVI a intentar una profundización en las observaciones relativas a grupos concretos de vegetales, pero sobre todo de animales. Una corriente conservadora, que en un principio parte de una admiración acrítica de los textos de la antigüedad, pero sobre todo un deseo de difundir las concepciones naturalistas de los antiguos, irá paulatinamente cediendo terreno ante las posibilidades dinámicas de creación implícitas en

(*) El presente estudio, que forma parte del proyecto investigádor «Felipe II en el Escorial: Biblioteca y decoración palaciega», pudo realizarse gracias' a una beca concedida por el Patrimonio Nacional. . 
los nuevos descubrimientos dando lugar a las primeras tentativas de explicación "positiva» de los fenómenos naturales.

En este empeño, el libro renacentista juega un papel importante: la ilustración del libro de historia natural (3), ayudada por las nuevas aportaciones de la teoría de la perspectiva que dan sistema y medida a la construcción de figuras en el plano y en el espacio (4), deja de cumplir una función meramente ornamental para convertirse, sobre todo a partir del siglo XVI, en la explicación de un texto que se orienta paulatinamente hacia la restitución fiel de la realidad, del mundo visible, convertido ahora en realidad sensible ponderable y mensurable; la naturaleza empieza a ser considerada como un sistema (4) que, siendo armónicamente modulado por fuerzas divinas acordes a los ritmos de la vida (5), puede ser analizado según métodos racionales en la observación y reflejo de la realidad.

Nace el pintor científico que ahora necesita de la colaboración y buen oficio del dibujante que sabe representar el mundo natural conjugando lo «necesario y lo bello» de acuerdo a un espíritu de investigación «bien temperado»; las leyes de la perspectiva (6) se utilizan en efecto para una descripción que se orienta hacia un cierto realismo gráfico que, conforme al principio leonardesco de que «la pintùra más digna de alabanza es la que más se asemeja a la cosa imitada», trata no sólo de reflejar nuevas formas aisladas, sino también de hacer un estudio comparado de estas formas para integrarlas en complejos sistemas taxonómicos (7).

Por otra parte, la fijación que supone lo escrito y multipliçado repetidamente a través de la imprenta sirve también a los nuevos ideales de una enseñanza en la que el profesor debe mostrar de forma adecuada, fidedigna y sistemática a los estudiantes las estructuras biológicas mediante unas ilustraciones que tienen que funcionar como soporte del texto. Y la publicidad y multiplicación de saberes que incorpora la imprenta permite, además, que en las universidades se realicen unas lecturas que aseguran una mayor difusión de obras y polarización de teorías que redundará en un progreso general de todas las ramas científicas. Como ha dicho Hall: «la lógica del naturalismo, la de la escuela y la de la imprenta se combinaron para crear un nuevo tipo de ciencia escrita basada en la observación» (8). Y en este sentido, los intercambios entre impresores, dibujantes y profesores sirve a los fines de un nuevo lenguaje visual que tiende a superar una ciencia académica aristotélica esclerotizada (9).

Estos grandes avances de la imagen impresa se dejan sentir sensiblemente en las obras de los grandes zoólogos del siglo XVI: en efecto, las representaciones animales de Gesner, Rondelet o Belon, aunque sumarias y 
repletas de inexactitudes, son cada vez más fidedignas, y se van acercando hacia un realismo, incluso a cierto "naturalismo" gráfico. No obstante, necesidades clasificatorias imponen todavía representaciones gráficas bastante ligadas a una iconografía tradicional: predomina sustancialmente una cierta repetitividad (10). Las necesidades clasificatorias imponen una imagen en las que se tiende a destacar las características más evidentes para subsumirlas en catálogos todavía muy estilizados que, para hacer posible el reconocimiento de la especie, desembocan en una especie de esquematismo, tipificación, rigidez y estereotipo.

\section{Vuelta a los clásicos, vuelta a la naturaleza}

El punto de tensión máxima en la dialéctica tradición-modernidad se produce cuando las novedades naturalistas encontradas en el Nuevo Mundo no hallan su confirmación en la autoridad, todavía indiscutida, de Aristóteles (11) o contradicen los testimonios de la Historia Natural de Plinio (12). Entonces el naturalista intenta una "adaptación»: una modalidad radical de crítica humanística a los textos toma la forma de corrección (la finalidad es «adaptar» lo nuevo a lo clásico mediante la corrección o castigatio); en otras ocasiones tiene lugar un mero "ajuste» de textos o testimonios discordantes a través de la glosa o el comentario; otras veces el autor renacentista se vuelca hacia la pedagogía de la explicación. Diferentes medios de desigual eficacia e intensidad orientados a la finalidad coincidente de dar a la leyenda carta de naturaleza científica. Y del mismo modo que el humanismo filológico se propone desde Valla reencontrar los textos literarios en toda su pureza, hallar la pureza de un corpus, después de sus diferentes fuentes, Gesner, por ejemplo, utiliza en la historia natural la noción de castigatio:

«Encontrarás en este volumen no solamente la historia de los animales, sino además una masa de comentarios apropiados con numerosas correcciones aportadas por todos los naturalistas antiguos y modernos cuyas obras hemos podido leer, y particularmente los escritos de Aristóteles, Plinio, Eliano, Alberto Magno y los agrónomos» (13).

A veces el procedimiento se invierte y es la "realidad» la que se "ajusta» (id. est., se falsea) a las necesidades textuales. 
Se trata, pues, de un movimiento en doble sentido que pretende por un lado depurar, purificar de errores las fuentes antiguas y por otro acordar las novedades desconocidas a un saber preexistente cuando éste no puede explicarlas: de este modo el naturalista renacentista accede, mediante la crítica, a un nuevo saber sintético, que no sólo no hace tabla rasa de las fuentes antiguas, sino que además las purifica de acuerdo a las nuevas necesidades de la experiencia. Nace así una nueva síntesis explicativa de la naturaleza que sabe conjugar los postulados renacentistas de «la vuelta a los clásicos» con una "vuelta a la naturaleza».

\section{Enciclopedias y monografías: Gesner, Rondelet, Belon, Salviani}

Por ello no debe șorprender que en las primeras «monografías» naturalistas se incluyeran elementos que, desde una perspectiva moderna, pueden parecer contradictorios: dan çabida por una parte al experimento, asumen por otra la leyenda. .

Esta tensión también se traslada a los diferentes modos de presentar y organizar el saber naturalista:

A) El saber enciclopédico, mito de la cultura renacentista, alienta por una parte la compilación de mastodónticas enciclopedias que pretenden compendiar expositivamente en una sola obra la concatenación universal, identidades y jerarquización de los conocimientos acumulados desde la antigüedad: es una refundación global del saber, pero también una conservación de un patrimonio de conocimientos en la que se privilegia la erudición y que implica un gran esfuerzo taxonómico, una clasificación y también la afirmación de una nueva función didáctica que necesita de un método (14). No hace falta decir que aquí se da entrada a toda suerte de elementos literarios, alegorías zoológicas, jeroglíficos, proverbios... Para Foucault: «Hasta mediados del siglo XVII la tarea del naturalista era establecer una gran recopilación de documentos y signos, de todo aquello que, a través de todo el mundo, podía formar una marca» (15).

Los autores de estas obras son, pues, meros compiladores que, siguiendo el modelo pliniano y sus epígonos medievales, no se preocupan por penetrar una posible lógica interna del reino animal, limitándose a exposiciones de lo que podríamos llamar "datos adquiridos» (incluidas muchas leyendas y errores) en un orden de.cómoda repertoriedad y con una fatigosả propensión a digresiones moralizantes (16). 
Como ejemplo típico de enciclopedia (aparte de los ejemplos medievales de Thomas de Cantimpré cuyo Liber'de natura rerum ve la luz en 1233, o de Vincenzo de Beauvais que terminó su Speculum naturale hacia 1250) se cita a la Historia Animalium (1551-1621) de Konrad Gesner: la obra, que mantiene las divisiones aristotélicas del saber, pretende recoger todos los animales citados por los escritores antiguos, todo posible conocimiento sobre el reino animal no sólo de carácter científico, sino también literario, histórico, simbólico sin menoscabo de antiguas supersticiones y leyendas. La heterogeneidad del ingente material recogido no impide sin embargo la adopción de unos claros criterios taxonómicos.

B) Por otro lado, las monografías: al ser obras muy circunscritas y bastante profundas que tratan de argumentos específicos, permiten que la erudición vaya cediendo terreno ante la experiencia y privilegian la observación puntual y la verificación empírica del detalle.

Entre las monografías del fondo naturalista de la biblioteca privada de Felipe II sobresale por su importancia gráfica la obra del médico y naturalista italiano Ippolito Salviani Aquatilium animalium Historiae (Roma, 1554-1558) (17).

Salviani conjuga la utilización de tablas de nombres griegos; latinos e italianos con la de las denominaciones en lengua italiana de especies marinas: unas enormes tablas señalan qué naturalistas antiguos (Aristóteles, Plinio...) han identificado unas especies que, aunque todavía no se disponen de forma metódica, ya se agrupan por sus caracteres externos. Salviani dedica un capítulo a cada especie y lo divide en varias secciones:

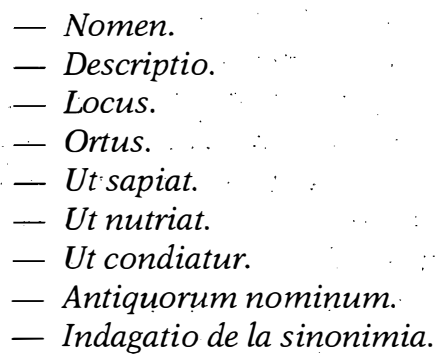

Así pues, esta obra de Salviani es un ejemplo donide se compaginan las enseñanzas de los autores antiguos con modernos criterios taxonómicos, onomásticos y de observación puntual.

Las obras de Rondelet (1507-1566) Libri de Piscibus Marinis libri XVIII (Lyon, 1554) y Universae. Aquatilium Historiae (Lyon, 1555) se encuadran 
también en la serie de monografías naturalistas, en esta categoría de libros documentales y técnicos cuya finalidad es dar una información visual, reflejo de una idea exacta de seres de la naturaleza a través de la imagen. La descripción verbal es concisa, minuciosa y exacta: la preocupación principal es hacer un inventario metódico. Para ello, la imagen aquí funciona como un documento visual:

«Nostre cher et bien amé maistre Gillaume Rondelet, nous a fait remonstrer que avec grans fraiz et labeurs auroit recuilly un gran nombre de poissons il auroit fait anatomie, et lever le pourtrait au plus près du naturel pour iceux insérer dans les livres, qu'il lui en auroit composés, et de longtemps y auroit prins gran peine et diligence pour en faire un histoire au plus vray qu'i lui auroit esté possible mettre en lumière avec lesditz pourtraits... (18).

«Hacer el retrato lo más cercano del natural para trazar una historia todo lo verdadera que le ha sido posible» (19).

Rondelet describe 200 especies marinas y 500 peces de agua dulce, conchas, moluscos, reptiles en 300 imágenes ejecutadas por Georgeseveid. Realiza excelentes observaciones sobre animales acuáticos (diferencia entre peces y cetáceos). Los grabados, aunque estéticamente inferiores a los de Salviani, muestran las peculiaridades morfológicas de muchas especies: aspecto de las escamas, espinas... A veces han sido realizados a partir de animales disecados.

Otro naturalista ampliamente representado en el fondo de privado de Felipe II es Pierre Belon (1517-1564): citaremos el ejemplar de la Histoire de la Nature des Oiseaux (París, 1555) donde Belon describe con gran cuidado a las especies ornitológicas que todavía clasifica según su tamaño, rasgos anatómicos, pero sobre todo por su habitat (aves que viven en el agua, que viven en tierra, en tierra y mar, pájaros pequeños que viven en setos) y de los que señala también su importancia gastronómica. Se ha señalado (20) que Belon sienta en esta obra las bases del método comparativo y dibuja detalladamente la primera lámina que establece los paralelismos entre el esqueleto humano y el de las aves:

«La extremidad del alón es como nuestros dedos: loṣ huesos dados por patas a las aves corresponden a nuestro talón; así como nosotros tenemos cuatro dedos menores en el pie, las aves tiene cuatro dedos». 
«Toda esta precisión no puede ser otra cosa que anatomía comparada para quien la ve armado de los conocimientos del siglo XIX".

«La descripción de Belon no hace más que destacar la positividad que ha hecho posible su época» (21).

Las calcografías de la obra parecen completamente «naturales» y realistas incluso cuando muestran formas que son imposibles y, correctas o no, estas ilustraciones - como en el caso de Leonardo- constituyen uno de los primeros intentos de «fotografiar» estructuras biológicas y también de hacer un estudio comparado de formas - sobre todo de los esqueletosde las diferentes especies.

Otra obra de Pierré Belon lleva el significativo título de "Portraits d'Oiseaux, Animaux, serpents, herbes, arbres, hommes et femmes, d'Arabie et Egypte» donde «Pierre Belon du Mans s'est premierement voulu employer a descrire le labeur des plantes et leur nature... Il ne s'estoit trouvé personne entre les autheurs tant anciens que modernes, qui eus fait voir les portraits des oiseaux avant luy». Una curiosidad y una gran preocupación por la exactitud llevan a Belon a realizar retratos, a recoger toda suerte de datos sobre medicina, ciencias naturales, geografía, historia de las costumbres y de las religiones. Ante todo son los descubrimientos lo que forma la materia de sus diferentes retratos o de sus observaciones. Así Cavellat, editor de sus obras, no sólo pondera la cualidad retratística de las imágenes de Belon, sino también su cualidad de documento visual que se hace sensible por las cualidades uniformes de precisión, exactitud en el detalle, sobriedad, seguridad de los contornos y finura de las sombras.

«Lors que nostre autheur escrivit ses Observations et voulant que ce fust un sommaire comme abbrégé des choses qu'il proposoit, luy sembloit assez, pour y faire voir les portraits, d'un oyseau, d'un poisson, d'un serpent, d'un arbe, d'un homme, d'une femme, telz que les verrez es suivants feuillets qui se ressentent de la majesté et grandeur d'un ouvrage modeste et bien experimenté».

Y curiosamente este naturalismo descriptivo de las ilustraciones de los libros de Pierre Belon alcanza también al autorretrato del autor, quien aparece con el atuendo de médico a la edad de 36 años, viejo prematuro con larga barba y rostro surcado por arrugas e incluso a las descripciones geográficas del capítulo que lleva el título de «Portrait de l'isle de Lemnos, du 
Mont Athos, chef des ceremonies de la religion des Grecs... suyvant la description des observations des singularitez des Pais Etranges».

En definitiva, el incipiente «empirismo» científico y el «naturalismo» iconográfico de estas primeras obras naturalistas son, pues, nociones que no dejan de plantear dificultades: junto a datos de descripción y representaciones naturalistas (sobre todo visibles en las monografías), aún perviven elementos de la tradición legendaria, filosófica o literaria (presentes predominantemente en las enciclopedias); junto a la observación minuciosa, la leyenda.

En los dos apartados siguientes se tratará de individualizar las fuentes y manifestaciones gráficas y literarias de estas dos corrientes que las más de las veces se presentan orgánicamente formandò parte de una unidad inescindible.

\section{El horizonte experimental}

\section{Fuentes}

La corriente experimentadora en zoología arranca de los atomistas (distinción de Demócrito entre vertebrados e invertebrados), pero hay que esperar a Aristóteles para que empiece a hablarse de la zoología como disciplina de observación (observaciones morfológicas bastante exactas), si bien debe tenerse presente que la visión global de la naturaleza del autor griego es básicamente teológica y no se asienta tanto sobre bases empíricas como en un estudio crítico de la filosofía presocrática y platónica. No obstante, como arranque "científico" nos sirve.

Los estoicos son responsables de una visión casi holística de la naturaleza hasta el punto de ser considerados precursores de un estudio analítico-empírico de carácter sistemático: así lo demuestra la importancia que atribuyeron al significado y etimología de las palabras, donde se hallan los primeros esbozos de los problemas de nomenclatura, onomásticos y terminológicos (22).

Durante los siglos XII-XIII aflora una producción de carácter técnicoaplicativo que toca aspectos de la agricultura y la caza con interesantes incursiones zoológicas y que, por su misma naturaleza, se orientarán hacia la certeza en la observación (23). 
Pero habrá que esperar a Alberto Magno (24) para que reviva la orientación aristotélica cuyas fuentes usa con sentido crítico. En las Quaestiones (1258-1260) y en De Animalibus Alberto introduce consideraciones médicas y veterinarias, describe exactamente no sólo la forma y las costumbres de muchos insectos, pájaros y mamíferos (descripciones tomadas parcialmente de Cantimpré), sino que además suministra noticias precisas sobre problemas biológicos generales tales como la ecología y la reproducción, realiza muchas observaciones personales (descripción del sistema nervioso ganglionar de los cangrejos y arañas) y agudas críticas que le llevan a considerar como fantasías a muchos monstruos plinianos y, consecuentemente, a excluir el origen diabólico de su monstruosidad, a ridiculizar la historia de la autocastración de Cástor, de la incubación de los huevós del águila por parte dél sol, a retomar la sistemática aristotélica y a insistir en el concepto de "Natura nọ fecit saltus»... ideas que se impondrán gradualmente en la segunda mitad del siglo XVI y que sólo fueron sistematizadas por Ulisse Aldrovandi a comienzos del siglo XVII.

El De Animalibus es uno de los mejorè ejemplos de cómo el sistema de hechos y lás explicaciones naturales proporcionados por la traducción de Aristóteles y de otros autores griegos estimularon a los filósofos de la naturaleza del siglo XII a hacer observaciones semejantes por cuenta propia y a modificar las explicaciones a la luz de esas observaciones. Los primeros dieciseis libros de De Animalibus son en efecto un comentario que incluyen el texto de la traducción de Miguel Scott de la Historia de los Animales, de Lás Partes de los Animales y Generación de los Animales de Aristóteles (25).

Ruralium Commodorum Libri XII (1304-1309) o De Proprietatibus Rerum de B. Anglicus (26) retoman estas ideas. Pero antes Bizantino Manuele Philes (1275-1345) en Peri zoon idioteos describe por vez primera especies animales.

Pero los ejemplos citados son casos aislados: en gèneral, èl hombre medieval obtiene su visión del mundo de una doctrina de la cual la experiencia empírica puede ser, en el mejor de los casos, una confirmación, pero no una verificación.

\section{Contenido intelectual del libro:}

Se consignan:

A. Los nombres de los animales en diversas lenguas:

B. El área geográfica y habitat. 
C: La descripción de los animales.

D. Sus costumbres.

E. Su utilización médica y alimenticia.

Elementos que sientan las bases de una zoología descriptiva.

\section{Ilustraciones}

Pero donde mejor se muestra la pujanza de la tendencia experimentadora es en la representación gráfica: encontramos ya en el primer período de la Edad Media representaciones realistas de plantas y animales en los mosaicos de muchas iglesias de Roma, Rávena y Venecia. Durante el siglo XIII en pintores tales como Giotto o Spinello Aretino.

Leonardo se refirió a la pintura como "verdadera ciencia, la hija legítima de la naturaleza, porque ha nacido de la naturaleza misma o, por decirlo más correctamente, la nieta de la naturaleza, porque todas las cosas que llegan a nuestros sentidos han nacido de la naturaleza y la pintura ha nacido de estas cosas» (27). Por ello, el pintor que es capaz de registrar la evidencia visual no sólo colabora a un trabajo científico, sino que. también él mismo lo ha realizado, y por tanto, es científico (y tal es el caso paradigmático de Leonardo). El artista que, en el siglo XVI; colabora en la ilustración de los libros de Cartografía, Botánica, Optica, Zoología o Astronomía es también un científico: ayuda a extender un corpus complejo de conocimientos en el que también colaboran traductores, autores y editores (28): el conocimiento de la naturaleza se alcanza a través de las artes liberales (la amplia esfera de la actividad científica) y no a través de las artes mecánicas (esto es, las actividades necesarias para el experimento, disecciones, colección de especies, construcción y uso de aparatos científicos).

Ahora bien, ¿cómo opera la interacción entre el artista y el material científico? Para Ackermann (29) de tres modos:

1. Una primera relación «naturalista», que requiere de todo el refinamiento de las técnicas de la mímesis, presenta a los científicos y naturalistas los objetos y fenómenos de la naturaleza en toda su evidencia visual (natura naturans) (30). El artista restituye el equivalente de lo que podrían llamarse "condiciones de laboratorio", que reducen o eliminan las varia- 
bles que afectan a la apariencia del objeto. Estas variables externas para el artista - color, luz y oscuridad, atmósfera, diferencias espaciales- pueden controlarse mediante la eliminación de los efectos de un habitat o evitando los escorzos. Las variables internas - psicológicas o sociales- son restringidas mediante la elección de un objeto que genere un mínimo de "ruido", de elementos convencionales o emocionales (afecto, miedo, respeto o desprecio).

2. Una segunda relación, que puede llamarse conceptual, implica un ajuste de lo visto por el ojo a un ideal, concepto externo modelado a partir de modelos de naturaleza racional, normalmente matemática (natura naturata) (31).

3. Una tercera, que puede llamarse convencional, pretende la preservación de la imaginería tradicional y se deje influir por los esquemas recibidos. (32).

En el Renacimiento, la noción de naturalismo pictórico basado en la experiencia visual convivirá, pues, con una representación racionalmente estilizada y con una preservación de las imágenes legadas por la tradición medieval del libro manuscrito.

\section{Mitos y leyendas: La tradición literaria}

\section{Fuentes}

No es posible trazar siquiera un esbozo sucinto de las fuentes mítico-legendario que apuntalan una visión mágica en los libros de zoología renacentista (33): el arranque ideológico quizá se halle en los neoplatónicos y pitagóricos con su interés unos por la mística, otros por la magia de los números (34). Virgilio, en sus Geórgicas, transmite conocimientos falsos sobre la vida de las abejas. Cicerón y Plutarco a menudo gustan de moralizar y comparan las pasiones del hombre con las virtudes, a veces imaginarias, de los animales.

Entre el siglo III y IV d. de C. se privilegia un tipo de ejercitación retórica sobre los textos antes que la indagación sobre los hechos. Se mul- 
tiplican los manuales escolares y aparecen algunas enciclopedias, como la Historia Natural de Plinio, quien se interesa más por los monstruos y portentos que en los fenómenos verificables y en las especies bien definidas.

Durante la Edad Media prevalece en líneas generalès una cultura religiosa basada en el texto revelado, del cual se buscaba una interpretación, fuera ésta literal, mística o una gnosis esotérica (35).

Este corpus medieval es' enorme: incluye obras de cosmografía, tratados didácticos como los de Solino y San Isidoro : el Physiologus (siglo II al $\mathrm{XV}$ ) que fue editado en un considerable número de lenguas en un sinfín de ediciones y que ilustra perfectamente el carácter mágico-simbólico que la civilización medieval otorgaba a los animales; esta obra suministra en efecto un amplio material para una interpretación alegórico-cristiana de los animales que perduró durante toda la Edad Media constituyendo una inspiración para toda suerte de bestiarios pintados o esculpidos (36). Se difundieron también summas enciclopédicas como las de San Alberto Magno, Vincent de Beauvais, Thomas de Cantimpré o de Brabante, Robert Bacon, Bartholomeus Anglicus (37); summas teológicas como la de Santo Tomás y summas poéticas y filosóficas como la Divina Comedia de Dante, crónicas, libros de viajes (Libro de las Maravillas de Mandeville, Viajes de Marco Polo y Colón) (38).

El Renacimiento resucita esa categoría equívoca de los mirabilia que comprende tanto las maravillas de la naturaleza, como las «causas secretas» que presiden esta o aquella «singularidad» del mundo animal, como los verdaderos monstruos cuya descripción multiplican a su gusto los humanistas: en el fondo de Felipe II de la biblioteca de El Escorial destaca en este aspecto el Libri Mirabilium septem de Frederici Nauseae donde se ilustran los llamados "portentos" de la naturaleza, los monstri portenti. En las ilustraciones de Ambroise Paré o Sebastian Brant en la Narrenschif se hacen aparecer toda suerte de diablos y animales emboscados: los monstruos de Brant, Jacob Rueff o Cornelius Gemma no son literarios como los de Schedel, Mennel, Lycosthenes o Wolf, sino que son «individuales" y tienen pretensiones de historicidad y para ellos se crea una rama de la historia natural llamada teratología. El'resultado se ha obtenido a partir de la ordenación metódica e interpretación arbitraria de un cúmulo de conocimientos provenientes de fuentes clásicas 'y postclásicas que han sido tratados con los instrumentos que proporciona la incipiente investigación anatómica y biológica renacentista. La aproximación estricta a los hechos queda oscurecida por el indiscriminado tratamiento 
de «casos»: criaturas mitológicas, monstruos imaginarios y descripciones generales se ponen al mismo nivel que las observaciones directas. En muchas obras del siglo XV el diablo es frecuentemente el héroe de las aventuras, así en el Libro de Belial (Estrasburgo, 1480). En las Fábulas de Esopo de Sebástian Brant (Basilea, 1501) aparecen diablos: también citaremos los grabados de Durero que representan a la Bestia del Apocalipsis. Otras veces, la inclusión de lo anómalo-monstruoso se justifica invocando a la Biblia: así, Jean d'Arras en su Melusina acude a la autoridad de David.

A esta sucinta enumeración cabe añadir la influencia de la Cábala judía, la Cábala cristiana, el biblismo intransigente del pensamiento protestante en sus comienzos: el nombre hebreo de los seres vivos es el único nombre auténtico y su estructura filológica explica las propiedades más singulares de la planta o el animal. A ello se añadirían las aportaciones de los poetas del Renacimiento cuando se refieren al Génesis y en concreto al relato de la Creación: el hombre, por delegación de Diọs, impone nombre a diversos animales. Se trata de un lirismo que se pretende al mismo tiempo religioso y científico.

En definitiva, condiciones de alta metafísica y alta teología confluyen en este punto con preocupaciones filológicas para designar las especies por parte de «esa extraña especie de historicismo que se da entre los pioneros de la ciencia moderna que les lleva a profundizar en la tradición hermética hasta el punto de considerar su ciencia como un redescubrimiento de antiguas verdades que un día fueron claramente percibidas por los dotados e incorruptibles fundadores de la filosofía» (39).

Para concluir este apartado sólo queda apuntar que la admisión de lo fantástico-legendario en la literatura naturalista renacentista no sólo deriva de una sumisión casi inconsciente a estas fuentes clásicas y medievales sino que además, en muchos otros casos, responde a la necesidad de los naturalistas de crear (esto es, de inventar como hipótesis de trabajo) nuevas variedades taxonómicas ante la imposibilidad de subsumir en las ya existentes las nuevas especies descubiertas en el Nuevo Mundo (en este caso el elemento fantástico deja de ser un factor conservador para convertirse en un elemento empírico que espera ser verificado - ratificado o corregido- con nuevas aportaciones); otras veces, la imagen grotesca o fantástica se adopta de un modo ideológicamente más consciente: la imagen fantástica es una reacción frente al estrecho control de lo verosímil contrarreformista que, al haber reducido lo cierto a lo conocido y posi- 
ble, forzó a la leyenda a refugiarse en lo inverosímil, lo fabuloso y lo monstruoso.

\section{Contenido intelectual del libro}

A) Elementos literarios: Las aportaciones procedentes de las epopeyas clásicas de la antigüedad y de una amplia gama de novelas del género animalesco como el Roman de Renard, el Roman de Fauvel (siglo XIV), de la mayoría de los bestiarios, la mitología, las novelas de caballerías, la poeșía encuentran una acogida muy favorable (40).

B) Elementos religiosos: La consignación de cuestiones tales como la sepultura de los animales, qué animales son sagrados; las relaciones entre los dioses y los animales, los sacrificios de animales derivan de consideraciones religiosas heredadas del paganismo, del cristianismo y sobre todo de la Biblia.

C) Elementos mitológico-alegóricos: los griegos simbolizaban mediante figuras de animales las edades del tiempo y divinizaban el día en doce horas colocadas cada una bajo el signo de un animal. La astronomía crea un bestiario y las constelaciones llevan nombres de animales que están relacionados con la mitología antigua. La heráldica se sirvió del animal para sus emblemas, sobre todo de los seres mixtos: Una amplia literatura renacentista versa sobre proverbios en los que se habla de los animales que desempeñan un papel simbólico: así en la abundante literatura emblemática - los Emblemata de Alciato (41) - el rasgo naturalista de la especie cede su puesto a una representación emblemática teñida de elementos literarios y filosóficos.

\section{Ilustraciones}

Resulta curioso observar cómo un número reducido de modelos iconográficos se repiten en diferentes libros para representar los mismos monstruos: se trata de representaciones teratológicas que se pretende "objetivas», "médicas», que desean dar cuenta no tanto de la existencia real de monstruos como hacer un inventario de monstruosidades reales que pu- 
dieron haber existido. Pero esta distinción es moderna y en los primeros libros impresos no existía.

\section{Aristóteles y la experiencia}

Pero donde mejor se muestra, con todas sus contradicciones, la complicada relación progreso-tradición en la ciencia zoológica del siglo XVI es en la actitud que los naturalistas adoptan frente al legado aristotélico: la ciencia procede de Aristóteles y Aristóteles la domina. Los científicos trabajan en función de Aristóteles, trabajan porque Aristóteles ha trabajado (42) y quienes experimentan lo hacen también porque Aristóteles lo hizo.

Relación, pues, con el Aristóteles experimentador.

Sobre este punto es interesante observar la mentalidad que guía la investigación de Belon a la conquista de la flora y fauna, y cómo las va a reconstituir. No parte a la aventura a la búsqueda de animales y plantas. No. Primero acude a la biblioteca, y allí confecciona una fauna y una flora completa: sólo después irá a la superficie del globo para ver si el globo verifica lo que dice Aristóteles, para confirmar que las cosas son como Aristóteles ha dicho que eran. Actuando así es sincero, sinceramente observador y sinceramente aristotélico: estos dos elementos definen paradójicamente lo que llama «natural».

Cuando, por ejemplo, leemos la expresión «natural» en las palabras de Pierre Belon [«il n'y a description, ni portrait d'oiseaux... qui ne soit en nature et que n'ait esté devant les yeux des peintres» (42 bis)], Aristóteles forma parte de esta naturaleza, de este "verdadero retrato» o incluso de esta «verdadera representación»:

\footnotetext{
«Me propuse reunir riquezas de tierras extrañas y puesto que el conocimiento de estas últimas no era fácil, antes quisimos extraer la perspectiva de sus efigies de los libros de nuestros antepasados para imprimirlos en nuestra idea. $Y$ sólo entonces nos atrevimos a ir a buscarlos a los países extranjeros, no esperando otra recompensa para nuestras penas que la de verlos en vigor» (43).
}

La recompensa del viajero es encontrar a los animales tal y como los había descrito Aristóteles: 
"Con gran esfuerzo y muchos gastos. he buscado en nuestro mar de Languedoc en Francia, en Italia y en otros lugares diversos peces. Mis amigos también me los han enviado. Los he abierto y diseccionado. He contemplado diligentemente todas sus partes exteriores e interiores. A ello he añadido los testimonios de Aristóteles, Teofrastro, Plinio, según la doctrina de los cuales he nombrado y representado los peces de manera fiel y tratado adecuadamente» (44).

Empleando la expresión de Claude Bernard, podemos concluir diciendo que en estos primeros naturalistas el testimonio de Aristóteles desempeña el papel de «idea experimental».

\section{Conclusión}

Durante el Renacimiento, en conclusión, la experimentación, ayudada por los progresos «naturalistas» de la xilografía, un Aristóteles depurado, convivirán con la leyenda, la filología, las imágenes simbólicas y el legado medieval creando una nueva síntesis naturalista punto de arranque de la ciencia naturalista moderna. De modo que el significado epistemológico de esta ciencia natural sólo podrá entenderse desde una perspectiva holística, entendiendo a la zoología como una summa variopinta de saberes, de factores diversos que formaban parte la cultura de la época:

«Hasta Aldrovandi la historia era el tejido inextricable y perfectamente unitario de lo que se ve de las cosas y de los signos descubiertos o depositados en ellas: hacer la historia de una planta o de un animal era lo mismo que decir cuáles eran sus elementos o sus órganos, qué semejanzas se les puede encontrar, las virtudes que se les atribuyen, las leyendas e historias en las que ha estado mezclado, los blasones en los que figura, los medicamentos que se fabrican con su sustancia, los alimentos que proporciona, lo que los antiguos dicen sobre él, lo que los viajeros pueden decir. La historia de un ser vivo era este mismo ser, en el interior de la red semántica que le enlaza con el mundo. La partición, para nosotros evidente, entre lo que nosotros vemos y lo que los otros han observado, transmitido o creído ingenuamente, esta.tripartición - tan sencilla en apariencia y tan inmediataentre la observación, el documento y la fábula no existía aún» (45). 
El ideal galileano de las ciencias basadas exclusivamente en la experiencia y en las demostraciones matemáticas sólo irá afirmándose muy paulatinamente durante los siglos XVI y XVII.

\section{NOTAS}

(1) Del fondo privado de Felipe II citamos a modo de ejemplo de libros de viajes, $L a$ Description de l'Afrique de J. LEON (1556, Lyon) donde hay pormenorizadas descripciones geográficas y de animales "tanto acuáticos como terrestres" o La Cosmographie de Levant de F. André Thevet (1554) (Lyon, Jean de Tournes), donde, junto a escenas de caza e imágenes de género, las xilografías representan diferentes especies animales.

(2) «Los ejemplos aportados nos demuestran que durante el siglo XVI ya se poseían informaciones correctas y de impresionante realismo sobre las formas de vida característicás del Nuevo Mundo. De ahí derivará una nueva visión de la naturaleza, distinta de una región a otra, en modo alguno uniforme y homogénea, planteándose en consecuencia nuevos y graves problemas relativos a la historia tradicional del Diluvio. Es entonces cuando, partiendo de una visión transformada de la naturaleza, se comienza verdaderamente a estudiar la distribución geográfica de las plantas y animales». CoḤen (1960). La science au sézième siècle, París.

Sobre la influencia de los descubrimientos geográficos en la historia natural europea es especialmente importante el estudio de A. W. CROSBy (1972), The Columbian Exchange: Biological and Cultural Consequences of 1492. Westport, Conn. Sobre la influencia en la zoología, véase de E. CALlot (1951), La Renaissance des sciences de la vie au XVI siècle (París).

(3) Los mejores estudios generales sobre la ilustración en el libro naturalista son: por lo que hace a la botánica, la obra clásica de W. BLunT (1950), The Art of Botanical Illustration, Collins, 14 st. James Place, London y el tratado de C. NIssen (1966), Die Botanische Buchillustration, 2 Aufl, Stuttgart: A. Hierssemann, 3 t. en 1 vol.

(4) Para la concepción orgánica de la naturaleza, ésta es un ser vivo que tiene "alma» y lucha por un fin: es un estado de crecimiento orientado a una necesidad y sólo puede ser descrita mediante analogías, pues se concede gran importancia al mito y al misterio. Para esta concepción la naturaleza es esencialmente algo imposible de conocer, algo demasiado maravilloso con para ser captado por los mortales. Quizá por ello el Renacimiento, que hizo suya esta idea orgánica de naturaleza, es mucho más rico en símbolos y mitos que la época de la revolución científica (cuando se impone la concepción mecanicista). G. BRoBERG (1985): Natural History Frontispieces and Ecology en The Natural Sciences and the Arts. Aspects of Interaction from the Renaissance to the 20 th Century. An International Symposium. Acta Universitatis Uppsala.

(5) La naturaleza considerada como un todo en el que sería erróneo separar el estudio de la naturaleza orgánica de la inorgánica. Los aristotélicos, los platónicos y los paracelsianos del siglo XVI concebían al mundo como un ser vivo y no es raro leer descripciones teó- 
ricas de la fecundación de la tierra por semillas astrales y del consiguiente crecimiento de los metales en vetas. Muchos consideraban este crecimiento análogo al del feto humano.

(6) PANofsky (1980): Perspectiva como forma simbólica. Tusquests.

(7) Por otra parte, la imprenta ejerce una considerable influencia sobre el estudio del mundo natural porque además estimula un mecanismo de "fedd-back", esto es, esta información, una vez impresa, puede ser "comprobada" con el modelo natural y corregida en su caso en las sucesivas ediciones y subsiguientes trabajos [E. L. EINSENSTEIN (1979), The Printing Press as an agent of Change, Cambridge, p. 485-488]. Conviene, sin embargo, notar que, en el caso de la zoología, estas correcciones son menores que en otras ciencias naturales, pues la mayoría de los manuales clásicos se basan en observaciones de primera mano y no tanto en la tradición clásica de Plinio o del Phisiologus.

(8) A. R. HaLl (1983): The revolucion in science, 1500-1700. London: Longman.

(9) E. L. Einstein (1979): The Printing Press as an agent of Change. Cambridge University Press.

(10) Sobre esta repetitividad en los libros de zoología, véase el artículo de W. B. AsHWORTH, JR. The Persistent Beast: Recurring Images in Early Zoological Illustration: el ejemplo tipo nos lo suministra la imagen del rinoceronte de Durero (grabado de 1505). Cole (1953) demuestra (The History of Albrecht Durer'rs Rhinoceros in Zoological History. E. A. Underwood, Oxford) que la figura de Durero fue el prototipo de los rinocerontes que se repitieron a partir de entonces en los tres siglos siguientes (en GESNER, ALDROVANDI y JONSTON, entre otros)

(1i) Fue considerable, durante los siglos XVI y XVII, la difusión de los libros de filosofía natural de Aristóteles: sólo en el fondo privado de la biblioteca de Felipe II en El Escorial ya encontramos una buena representación: así, una edición con el Libri meteorum, Libri de Animalibus, De Generatione et corruptione (París, 1552) comentado por Io. Genesio Spulvedam o un volumen que, bajo el título genérico de Parva Naturalis (Venecia, 1560), recoge diversas obras del autor griego (entre ellas De Animalium motore).comentadas por N. Leoniico Thommaeo.

(12) En realidad, el texto de Plinio era tan vulnerable a la crítica humanística como los textos de otros autores de la antigüedad. ERmolao Barbaro (1454-1493) se enfrentó a los treinta y siete libros de la Historia Natural para escribir una obra que rivalizaba con ella en extensión. En sus Castigationes plinianae (1492-1493), BARBARO erradicaba los errores artículo por artículo centrándose especialmente en el estudio de las fuentes antiguas que utilizó Plinio, sin cuidarse apenas en aportar nuevas observaciones sobre las plantas y los animales.

Del fondo de Felipe II en la Biblioteca de El Escorial se consultaron las castigationes a la Historia Natural de Plinio de Franciscus MASSARI (In nonum Plinii de Naturali. Historia Castigationes Annotationes, Basilea, 1537) que prueba que los autores del momento eran conscientes de los errores sin fin de la enciclopedia pliniana.

Esta disfunción entre el descubrimiento geográfico y el texto antiguo (en sus formas de libros de viajes, cuento o mito) ha sido estudiada en el caso de los Diarios de Colón por J. GiL (1989) en la reciente obra Mitos y utopías del Descubrimiento (Tomo I: Colón y su tiempo): ver p. 24: «La fauna y la flora indiana».y p. 29: «Monstruos de Oriente» (Madrid, Alianza Universal).

(13) GESNER (1560). Historia animalium. (TIGURI). 
(14) Sobre los modelos de literatura enciclopédica en la antigüedad clásica véanse los artículos de S. L. JACKson (1973), «Towards a History of the Encyclopedia: From Amenemope of Egypt to the Collapse of Greek in Rome» y el de F. J. WITTY (1976): "Reference books of Antiquity", publicados en The Journal of Library History.

(15) M. Foucault: Las palabras y las cosas (1974) (México).

(16) En este sentido es significativo el procedimiento de Gesner en su Historia Animalium: primero trata de la nomenclatura del animal en todas las lenguas conocidas (interpretación etimológica al modo medieval), después describe la apariencia exterior (forma), el habitat y comportamiento (victus y mores), su crianza e incubación. Datos éstos que sólo. son prerrequisitos para las secciones que siguen que van más allá de la descripción y observación: significados morales (moralia) provenientes de interpretaciones antiguas y medievales; significados metafóricos, símiles, proverbios, fábulas. Consagra una sección autónoma a otras aplicaciones (user allii): usos prácticos en cocina y en medicina que ocupan un lugar secundario en relación a las lecciones morales. En definitiva, el campo de la precisa descripción verbal y gráfica de los hechos empíricamente establecidos convive y se subordina al reino de los significados generales y de los potenciales significados naturales. En el protestante Gesner preexiste una preocupación religiosa: el estudio de las criaturas vivas conduce al hombre a la contemplación de su Creador y por eșo las citas de Aristóteles conviven con las referencias a las Sagradas Escrituras para justificar el estudio de determinados aspectos de historia natural.

(17) SALVIANI está estrechamente vinculado al papado (médico personal de Julio II, Pablo IV y del Cardenal Cervini, quien sufragó los gastos de las obras). Entre 1551 y 1568 es profesor de medicina práctica en la Sapienza.

Las bellas calcografías de Aquatilium Historiae, ejecutadas por Bernardo Aretini y sobre todo por el lorenés Nicolás Beatrizet, sorprenden por las gradaciones y rica matización de los tonos cromáticos con que se representan las especies marinas.

(18) Rondelet (1554): Libri De Piscibus Marinis (palabras del privilegio) (Lyon).

Esta cita del prefacio del libro de RONDELET puede compararse con las siguientes palabras que escribe LEONHARD Fuchs en De Historia Stirpium (Basilea, 1542) refiriéndose a las ilustraciones de su compilación botánica: «He evitado deliberadamente la deformación o las distorsiones de la forma natural de las plantas huyendo de las sombras y de otros procedimientos todavía menos necesarios mediante los cuales los dibujantes intentan a veces conquistar la gloria artística...».

(19) Y esta incipiente tendencia de la obra de RONDELET a reflejar una realidad natural a través de métodos "empíricos» y representaciones "naturalistas» en el terreno concreto de las especies marinas es especialmente sorprendente en este campo de la zoología, a la sazón repleto durante la Edad Media de abundantes connotaciones religiosas y simbólicas derivadas sobre todo de una secular tradición judaica originaria preponderamentemente de la exégesis de episodios del Nuevo Testamento tales como la pesca milagrosa, la multiplicación de los panes y los peces... El pez era el símbolo cristiano por antonomasia y la alegoría del pez, a través de los testimonios de los Padres de la Iglesia, se convierte en un medio didáctico, moralizante y edificante dotado de una fuerte simbología, e incluso se transmite a autores tan "empiristas» como Alberto Magno (ver, por ejemplo, la descripción del pulpo en De Animalibus, XXI 40). E incluso, si por una parte durante los siglos XII y XIII, se asiste a un renacimiento de los estudios anatómicos alentados por un deseo de dar a conocer ciertas particularidades perceptibles directamente, esto es, sin mediación litera- 
ria o religiosa (por ejemplo, en las Quaestionés naturales de Adelardo de Bath), estas características anatómicas eran vistas bajo un prisma funcional y reconducidas a una concepción finalista que exaltaba el orden establecido por Dios (Natura enim nihil facit otione no se cansa de repetir Alberto). En la búsqueda de principios científicos naturalistas lás respuestas que se daban a los problemas etiológicos eran a menudo puramente imaginativos o construidas racionalmente sobre elementos fantásticos que tomaban como modelo las costumbres y el comportamiento del hombre. De este modo, el mundo de los peces continuó siendo hasta el Renacimiento el ámbito cerrado (como el propio habitat acuático) que - había sido durante siglos y ofreciendo un espacio inagotable a las fantasías y prestándose a la constrúcción de un imponente edificio de'nociones y creencias heterogéneas en una tenaz sedimentación de conceptos que conseguirá mantenerse sustancialmente estática. Teniendo presente todo este vasto sedimento, se apreciará adecuadamente el valor innovador de monografías como el Libri de Piscibus de Rondelet (donde, por ejemplo, el autor francés señala las diferencias anatómicas entre los sistemas respiratorio, nuitritivo, vascular y genital de los vertebrados acuáticos que respiran por branquias y pulmones, dibuja el delfín vivíparo y el tiburón ovovivíparo, intenta descubrir correspondencias morfológicas entre las partes de los corazones de los mamíferos y de los peces...) o como el De Aquatilibus de Belon quien, por ejemplo, gracias a disecciones de tres tipos de cetáceos, pudo comparar su esqueleto y corazón con el del hombre, dibujó fidedignamente la marsopa unida por el cordón umbilical a la placenta y al delfín con un recién nacido todavía envuelto en las membranas fetales...

(20) M. Foucault: $O p$ cit.

(21) M. Foucault: Op. cit.

- (22) Del fondo privado de Felipe II de la biblioteca de El Escorial, véase Naturalium Quaestiones Libri VII de L.A. SENECA (1552) anotadas por Matthaes Fortunati (Venecia: Aldo Manuzio) que atestigua la difusión de estas obras naturalistas durante el Renacimiento.

(23) Véanse las obras de los geopónicos latinos que fueron editadas sucesivas veces durante el siglo XVI. Del fondo de la biblioteca privada de Felipe II del Monasterio de El Escorial citaré: Des choses rustiques de Columela (París, 1552). También pueden consultarse obras de agricultura como el De Agricultura de Constantini Caesaris (Basilea: Froben, 1538) o Les Treze livres des choses rustiques de Palladius Rutilus (París, 1554) en la traducción de Jean Darce.

Un ejemplo de libro de cetrería del fondo privado de la biblioteca de Felipe II es Le livre de l'art de faulcônerie de JEAN FRANCIERS.

En esta literatura técnico-aplicativa ocupan un lugar privilegiado los libros de veterinaria: del fondo privado de la biblioteca de Felipe II cito la Hippiatria de LAURENTII Rusi (París, 1531) o la más célebre, Verterinariae Medicinae, Libri III de IoHANNE Ruellio (París, 1530).

También se pueden citar textos prácticos como el De arte venandi cum avibus de FEDERICO II DE SUECIA (1194-1250), obra basada en las enseñanzas de Aristóteles y. en varias fuentes musulmanas donde se funde una sólida experiencia práctica con la capacidad de observación de estructuras y de comportamientos, la experimentación (experimentos sobre la incubación artificial de huevos) con la cultura crítica y la intuición de un Alberto Magno. Se tiene à FEDERICO II como primer verdadero ornitólogo que realiza observaciones anatómicas que le aseguran un puesto en la anatomía comparada. La obra comienza con una introducción zoológica sobre la anatomía y costumbres de los pájaros y sigue des- 
cribiendo la crianza y alimentación de los.halcones, el adiestramiento de los perros para la caza, los diferentes tipos de halcones, grullas y garzas. Cuando Federico se refiere a otros tratados prácticos de cetrería, no duda de calificarlos como "embusteros e inadecuados", como tampoco vacila en calificar a Aristóteles de libresco. Las 900 figuras de aves son exactas y revelan también una atenta observación (ya sea del plumaje de.las aves o de la representación de pájaros en vuelo).

(24) Puede consultarse: Goldstein-Preaud, T. (1981), Albert le Grand et les quaestiones du XIII siecle sur le De Animalibus d'Aristote, Hist. and Phil. of Life Sciences, Pubbl. St. Napoli, Sect. II, 3: 61-77.

WeISHEIPL J.A.O.P. (1980), Albertus Magnus and the Science. Commemorative essays. Pontifical Inst of Medieval Studies, p. 412.

(25) El moderno deseo experimentador de Alberto también puede verse cuando dice del ave fénix, considerada como símbolo de la resurrecçión, que era estudiada más por los teólogos místicos que por los filósofos de la naturaleza o su agrupación de los animales en grupos basados en semejanzas morfológicas o reproductoras, otras veces en grupos ecológicos (así distingue animales voladores (volatilia), nadadores (natatilia), andadores (gressibilia) y reptantes (reptiles). Véase: A. C. CRombiE: Augustine to Galileo: Sciencie in the Middle Ages, 5 th to 13 th Centuries.

(26) De la difundida enciclopedia naturalista de B. Anglicus: De Propietatibus Rerum (primera edición: Basilea, 1470) cito el incunable del fondo privado de Felipe II de la biblioteca escurialense que lleva el título de El Libro de proprietatibus rerum (Tolosa: Henrique Meyer, 1494) traducido al castellano por Vicente de Burgos: el libro de Anglicus (sic), del que aparecieron no menos de veinticinco ediciones antes de final del siglo XV, dedica un capítulo específico al estudio de la zoología (De Animalibus).

(27) LeONARDo da Vinci. Tratado de la Pintura.

(28) Sobre este nuevo status del pintor científico es muy aleccionadora la xilografía coloreada que aparece en la página 877 de De Historia Stirpium de Leonardo Fuchs (Basilea, 1542); Albrecht Meyer, quien dibujó las plantas a partir de modelos naturales, Heinrich Fulmaürer, que trasladó los dibujos a las planchas y Veit Rudolf Speckle, que los grabó, aparecen retratados en una ilustración de página completa ejecutando sus labores respectivas muy cerca de la efigie del propio Fuchs. Con esto, por lo menos, se ha querido situar en igual rango a los pintores que al autor de esta compilación botánica.

(29) Véase la ponencia de ACKERMAN (1985) en The Natural Sciences and the Arts. Aspects of Interaction from the Renaissance to the 29th Century. An International Symposium. Acta Universitatis (Uppsala).

(30). Cuando el naturalista se refiere a la ilustración de sus libros con locuciones tales como "del natural, "verdaderos, retratos"», "verdadero» o incluso de "verdadera representación" es porque existe esta observación, este deseo incipiente de experimentación. Así BELON dice en sus Observations des plusieurs singularitez et choses memorábles trouvées en' Grece... (París, 1553):

"Aristóteles, hablando de este pájaro, ha mostrado que había mirado su anatomía interior».(41).

En este mismo sentido ver la cita de Fuchs de la nota (18).

(31) J. Bialostocki (1985) (The Renaissance Concept of Nature and Antiquity. Acts of the Twentieth International Congress of the History of Art II, Princenton, p. 19-30) afirma

Asclepio-I-1992 
que los primeros escritores del Renacimiento se refieren explícitamente a esta distinción entre natura naturans y natura naturata.

(32) ACKeRMAn (op. cit.) piensa que esta tercera corriente sería la que, paradójicamente, caracterizará en un primer momento a la ilustración naturalista renacentista: como los textos científicos pionieros publicados en las primeras décadas de la invención de la imprenta eran ediciones de autores antiguos y medievales, el artista no representa el mundo como lo ve, sino que las xilografías se apoyan o imitan las iluminaciones de los manuscritos que han llegado a sus manos. En sus comienzos la imprenta era considerada como una máquina para "fabricar" manuscritos y también los tipos imitan lo escrito. Las primeras xilografías eran más decorativas que funcionales, pues los modelos medievales eran abstractos o simbólicos (como el pensamiento medieval mismo), y como las ilustraciones de los textos que sobrevivieron desde la antigüedad se fueron distorsionando a través de sus innumerables reproducciones, finalmente el resultado no sirve a finalidades prácticas.

- Pero quizá, en una segunda etapa, cuạndo el dibujante decide atender las demandas de exactitud por parte de los taxonomistas, progresa la mímesis y se desarrolla todo el potencial revolucionario que implicaba la imprenta para el libro de ciencia: cada copia individual duplicará una imagen que, esta vez sí, ha sido aprobada por el autor, y actuará no sólo como soporte plástico de la información autónoma dotada de valor intrínseco, e incluso, produciéndose una abrupta inversión de funciones, los textos llegarán a ser meros elementos auxiliares dedicados parcial o totalmente a explicar nominalmente y post facto la imagen científica.

G. LAPAGE (1961) (Art and Scientist, Bristol) piensa en cambio que natura naturans es el primer peldaño de una escala que también implica imágenes interpretativas y finalmente representaciones imaginarias que ocasionalmente pueden consistir en una libre toma de postura del artista frente a la realidad visual.

Parece ser que en materia científica, para acceder a los textos del pasado, se recurrió durante mucho más tiempo a los manuscritos que en otras ramas del conocimiento. En este sentido, L. FeBVRE-J. MARTIN (1958): L'apparition du livre (Edition Albin Michel, París).

(33) Para una imaginería de animales fantásticos en la Edad Media remitimos al estudio de KAPPER (1980): Monstres, démons et merveilles à la fin du Moyen Age (Payot, París) (traducción española, Ediciones Akal) que contiene una detallada tipología de monstruos medievales, analiza las funciones del monstruo en el alma humana, y las fuentes de conocimiento que considera que básicamente son tres: viajes, cuentos y mitos. Para un estudio del animal entendido como «abstracto espontáneo, objeto de una asimilación simbólica que testimonia la universidad y pluralidad de su presencia tanto en una conciencia civilizada como en la mentalidad primitiva» consúltese: G. DURAND (1979): Les structures anthropologiques de l'imaginaire (Introduction à l'archétypologie génerale), París: Bordas.

También puede verse de J. Baltrusartis (1983): Le Moyen Age Fantastique, Antiquités et exotismes dans l'art gothique. (Flammarion)

(34) En este sentido se manifiesta A. M. SimonetTA: La conoscenza del mondo animale dalla romanità al Medioevo.

(35) Así, en la Edad Media, se cita repetidamente el Libro de Job para iluminar sobre un pretendido doble status de los monstruos: 1) La maravilla que es emanación de un poder creador inconcebible por la inteligencia humana y 2) las fuerzas maléficas de carácter devorador y terrorífico (Behemot, Leviatán, Satán). 
Del fondo de la biblioteca privada de Felipe II véase la obra de PHILIPPI (sic.), In historiam Iob (Basilea, 1527).

(36) F. Mc Culloch (1960) en su obra Mediaeval an Latin French Bestiares (The University of North Carolina), donde estudia las diferentes versiones del Physiologus y su repercusión en los bestiarios fantásticos de la Edad Media. La define como «una compilación pseudocientífica y didáctica donde las descripciones fantásticas de animales reales o imaginarios, pájaros e incluso piedras se utilizaron para ilustrar puntos del dogma cristiano y moral». Así la sección dedicada al pelícano comienza con una cita del Salmo 102:6. La captura del unicornio se considera una representación alegórica de la Encarnación.

Por otra parte, H. Mode (1980) (Animales fabulosos y demonios, México: FCE) cree que muchos seres mixtos, como el león hormiga, el endrop, provienen de esta fuente.

(37) Ver nota 25.

(38) Véase el estudio de KAPPER (1980): Monstres, démons et merveilles à la fin du Moyen Age (Payot, París) (Traducción española, Ediciones Akal).

(39) A. R. Hall: Can the History of Science be History?

(40) Del fondo privado de Felipe II de la biblioteca de El Escorial, como ejemplo de literatura animalesca, cito una edición de las Fabulae de Esopo comentadas por Máximo Planude (Lyon, 1539).

(41) De entre las numerosísimas ediciones del fondo privado de Felipe II de la biblioteca de El Escorial cito la edición de los Emblemes editada en París en el año 1537 por Mace Bonhomme.

(42) Sobre la difusión de las obras naturalistas de Aristóteles en el fondo privado de Felipe II, véase la nota (12).

(42 bis) P. Belon. Histoire de la nature des Oiseaux, f. a4.

(43) En el fondo privado de Felipe II de la biblioteca de El Escorial hay dos ediciones de la obra: Observations des plusieurs singularitez et choses memorables trouvées en Grece, Asie, Judée, Egypte, Arabie et autres pays étranges (París, Guillaume de Cauellat, 1553); la segunda edición, también editada en París por Guillaume de Cauellat, es del año 1555.

(44) BELON. Histoire naturelle des etranges poissons (París, 1555).

(45) M. FoucaulT: Op. cit. 